\title{
O turismo religioso na sociedade líquido-moderna: apropriação da fé pelo trade turístico
}

\author{
Alan Faber do Nascimento* \\ Vitor Chaves de Souza**
}

\section{Resumo}

A despeito da irredutibilidade do sagrado, o turismo religioso, tal como o conhecemos hoje, ao invés de prestigiar o fenômeno sacro sui generis, preocupa-se imprescindivelmente com a manutenção da indústria turística per se. O objetivo do texto é demonstrar, sociológica e filosoficamente, a apropriação da fé pelo trade turístico na sociedade líquido-moderna. Para isso, a pesquisa parte da crítica, de fundo marxista, da sociedade de consumo e alcança os paradoxos do turismo, bem como a busca existencial por espaços saturados de sentido e a vivência da temporalidade com pretensão eterna. $\mathrm{O}$ artigo segue as intuições metodológicas de Hervieu-Léger, Zygmunt Bauman e Mircea Eliade. Empiricamente, a pesquisa orienta-se por autores das ciências humanas e da religião para a análise histórica e atual do peregrino contemporâneo e do nascimento do "eu moderno" no processo de consumo intrínseco aos mercados turísticos.

Palavras-chaves: turismo religioso; sociedade líquido-moderna; espaço sagrado; trade turístico; eternidade.

\section{Religious Tourism in a Modern-Liquid Society: Appropriation of Faith by the Tourist Trade}

\footnotetext{
Abstract

In spite of the irreducibility of the sacred, the religious tourism, as we know it nowadays, instead of prescribing the sacred sui generis phenomenon, is essentially concerned with maintaining the tourism industry per se. The paper demonstrates sociologically

* Pós-Doutor em Sociologia e professor do curso de Turismo e na Pós-Graduação em Estudos Rurais da Universidade Federal dos Vales do Jequitinhonha e Mucuri. Email: alanfaber@uol.com.br

** Pós-Doutor em Ciências da Religião e professor no curso de Filosofia e na Pós-Graduação em Ciências da Religião da Universidade Metodista de São Paulo. Email: vitor.chaves@ metodista.br
} 
and philosophically the appropriation of faith by the tourist trade in the modern-liquid society. For this task, having a marxist background, the research asks for the paradoxes of tourism, as well as for the existential search for meaningful spaces and the experience of temporality with eternal pretension. The article follows the methodological intuitions of Hervieu-Léger, Zygmunt Bauman, and Mircea Eliade. The research is empirically guided by authors of the human sciences and religion for the historical and current analysis of the contemporary pilgrim and the birth of the "modern self" in the process of consumption intrinsic to the tourist markets.

Keywords: religious tourism; liquid-modern society; sacred space; tourist trade; eternity.

\section{El turismo religioso en la sociedad moderna líquida: apropiación de la fe por el trade turístico}

\section{Resumen}

A pesar de la irreductibilidad de lo sagrado, el turismo religioso, tal como lo conocemos hoy, en vez de prestigiar el fenómeno sacro sui generis, se preocupa imprescindiblemente con el mantenimiento de la industria turística per se. El objetivo del texto es demostrar, sociológicamente y filosóficamente, la apropiación de la fe por el comercio turístico en la sociedad neto-moderna. Para ello, la investigación parte de la crítica, de fondo marxista, de la sociedad de consumo y alcanza las paradojas del turismo, así como la búsqueda existencial por espacios saturados de sentido y la vivencia de la temporalidad con pretensión eterna. El artículo sigue las intuiciones metodológicas de HervieuLéger, Zygmunt Bauman y Mircea Eliade. La investigación se orienta por autores de las ciencias humanas y de la religión para el análisis histórico y actual del peregrino contemporáneo y del nacimiento del "yo moderno" en el proceso de consumo intrínseco a los mercados turísticos.

Palabras claves: turismo religioso; sociedad líquida-moderna; espacio sagrado; turismo; eternidad.

\section{Introdução}

No clássico The Gaze of Tourist, de John Urry (1997), há uma interessante assertiva sobre a natureza do turismo contemporâneo. $\mathrm{O}$ autor nos chama atenção para o fato de que nos dias que correm tudo, absolutamente tudo, pode ser objeto de curiosidade turística. Não por acaso, à diferença de sua característica massificante do pós-guerra, quase sempre baseada no modelo sol, praia e mar, notadamente nos países tropicais, há hoje uma variada e multifacetada gama de atrativos turísticos de características ecológicas, culturais, históricas. Dentre esses segmentos, sem dúvida, o turismo religioso chama a atenção. Em primeiro lugar porque, ao redor do globo, são várias as destinações em que o motivo da viagem é o contato com o sagrado - o que gerou uma nova configuração para a tradicional geografia da fé, isto é, o Vaticano, para os católicos romanos; Meca 
para os muçulmanos; Jerusalém, para os judeus, muçulmanos e cristãos, e assim por diante. Segundo porque os diferentes credos passaram a contar com nichos específicos de viagens turísticas. E mais importante porque as fronteiras, que até então demarcavam os territórios entre religião e mercado (turístico), estão cada vez mais embaralhadas. O embaralhamento é traduzido por Zygmunt Bauman, em Vida para Consumo (2008), como a natureza própria da sociedade pós-moderna - ou, melhor, em sua conceituação, como algo intrínseco à modernidade líquida -, cujos valores interiores e exteriores dão lugar à reprodução de um modo de vida orientado pelo consumismo. Desse modo, ao invés de proporcionar ao indivíduo uma experiência original, o turismo religioso reforça as características líquido-modernas de uma sociedade integralmente mediada pelo consumo - e isso até mesmo quando nos encontramos em tempos e espaços sociais que, em princípio, os "vendilhões teriam sido expulsos".

\section{Os fundamentos do espaço do turismo religioso}

Na Europa, a cidade portuguesa de Fátima é um exemplo paradigmático daquilo que poderíamos chamar de um boom das peregrinações pós-modernas. Note-se que, no curto espaço de algumas décadas, o que antes era um espaço serrano, quase desabitado e dedicado à pastorícia, transformou-se num centro urbano onde se estima que, nos anos 2000, afluíam cerca de 5 milhões de turistas por ano (SANTOS, 2000). Seria possível arrolar uma série de causas para explicar o fenômeno turístico nessa cidade da península ibérica, desde os milagres que ali foram descobertos até o fato de que, segundo o Ministério do Turismo português, $75 \%$ do patrimônio histórico nacional ter cunho religioso. Agora, não se poderia deixar de mencionar, também, as visitas que João Paulo II fez a Fátima no início daquela década - evento, sem dúvida, religioso, mas, igualmente, midiático e televisionado. Daí a necessidade de qualificar essas peregrinações sob uma outra forma. Afinal, etimologicamente, peregrino designa "o estrangeiro, aquele que não pertence à sociedade local estabelecida” (STEIL apud ABMANSSSUR, 2003, p. 30). Trata-se, portanto, de uma palavra que, em sua origem, sugere o desconhecido, aquilo que está para se descobrir - ou mais precisamente "não é o homem que escolhe os lugares sagrados e os caminhos que a ele conduzem. Ele apenas o descobre" (WERNET apud PEREIRA et. all, 2008).

A era das "grandes narrativas" expandiu as fronteiras do conhecimento e, ao mesmo tempo, do comércio implícito em cada área do saber. O turismo reli-

Termo de Jean-François Lyotard para tratar as ideologias próprias da modernidade, In:

La condition postmoderne: rapport sur le savoir. 
gioso também está presente na principal economia do mundo como uma grande narrativa. Em sua fundação e formação histórica, os Estados Unidos não tinham uma religião oficial do Estado para construir uma identidade nacional. Segundo RICKETTS (2018, p. 43), a criação de geografias sagradas, constituídas em torno da natureza norte-americana, possibilitaram os mitos fundadores da república. Tais lugares, ao mesmo tempo sagrados naturais, construídos pela ação humana, abrangem, hoje, os Estados Unidos e correspondem, diretamente, a uma religião civil atraindo turistas. A vista disso, documentos como a Declaração de Independência são visitados com uma apreciação sagrados - ou, se quisermos, enquanto texto fundante de uma humanidade (cf. PUCHNER, 2017, p. 32), cuja atribuição de reverência assemelha-se a uma esfera sagrada. Os destinos turísticos sagrados, frequentemente construídos a fim de impregnar identidade a uma nação, provocam algo semelhante ao temor religioso e criam, consequentemente, um espaço onde os rituais públicos e as peregrinações modernas são diversamente encenadas. Há muito que as viagens aos Estados Unidos deixaram de se resumir a Disneylândia, Miami ou Las Vegas. Ao lado desses ícones da indústria turística norte-americana, pelo menos desde os anos 1990, chama a atenção as excursões organizadas por grupos adventistas de todo o mundo para a cidade de Batlle Creek, no estado de Michigan. Nesse exemplo, o que surpreende é o uso de um vocabulário herdado do marketing turístico pelas revistas oficiais da denominação para promover os passeios. É o caso da Revista Adventista do Brasil. Note-se que, em anúncio publicado na edição de dezembro de 1989, a revista destacava o chamamento para a Conferência Geral adventista com a seguinte frase "Venha viver a emoção de um roteiro histórico" (REVISTA ADVENTISTA apud FOLLIS, 2018). Na edição de maio de 1990, em anúncio para o mesmo encontro, lia-se "estão previstos vinte e três emocionantes dias, onde os participantes poderão conhecer as famosas praias americanas, o reino mágico de Walt Disney, as cataratas de Niágara, a capital adventista do mundo, entre muitos outros pontos de interesse turístico" (REVISTA ADVENTISTA apud FOLLIS, 2018, p. 57). Mais recentemente, em edição de janeiro de 2015, a publicação chamava a atenção para o número de brasileiros que visitavam os Estados Unidos em busca do patrimônio histórico adventista, a exemplo da sede mundial da igreja e do ministério da herança adventista (MHA), dando destaque para números que vinham crescendo anualmente e já alcançavam a cifra de 12 mil turistas por ano (REVISTA ADVENTISTA apud FOLLIS, 2018).

Já na parte latina do continente americano, não se poderia deixar de mencionar o turismo religioso na cidade peruana de Cuzco - tanto o voltado para as igrejas localizadas no seu centro histórico, a exemplo dos templos de San Blás e 
San Cristobal, que integram o chamado Circuito Religioso Arzobispal da cidade, quanto aquele voltado para os antigos territórios das civilizações pré-colombianas, caso do santuário religioso inca Machu Pichu. Segundo estudo realizado pela Universidade Nacional de San Antonio Abad del Cusco, a "indústria sem chaminés" em Cusco movimenta hoje 41 mil empresas turísticas, que, juntas, contribuem com 17\% do PIB regional, onde o setor turístico emprega dois a cada dez cusquenhos. O saldo desses números é uma economia do turismo altamente monopolizada. É o caso de Machu Pichu, cujo mercado turístico, impulsionado por ingressos na ordem de 1,7 milhão de visitantes ao ano, é controlado pela empresa Consettur, detentora dos direitos de exploração da estrada Hiram Bingham (que liga o município de Aguas Calientes com o santuário inca). Desnecessário dizer que essa rota de peregrinação contemporânea, de apenas $7 \mathrm{~km}$ de extensão, tornou-se uma mina de ouro - o preço médio cobrado é em torno de 24 dólares por pessoa, o que representa um lucro líquido anual de 64 milhões soles peruanos (211 milhões de dólares) para empresa (SALCEDO, 2018).

À vista desses exemplos - dentre os quais se vislumbram, conceitualmente, as três formas de turismo religioso, a saber, "turismo de base religiosa", "turismo para lugares sagrados" e "turismo religioso ou espiritual” (cf. RICKETTS, 2018), - o fato é que a explosão nos números do turismo religioso não existiria se não houvesse uma disposição interior para tal movimento. Há, a rigor, uma motivação de caráter ontológica para a visitação de lugares sagrados, unindo lazer e, na linguagem da fenomenologia, significação de mundo. Diferentes abordagens turísticas, com uma intenção prática: organizar, se quisermos, a vida interior do viajante. A inclinação para a organização da vida interior, na elevação do espírito, procura não apenas no sagrado a sua ordem mais legítima como também manter-se, de certo modo, equilibrado - pelo consumo significativo - na sociedade líquido-moderna.

Em O Sagrado e o Profano, Eliade orienta suas reflexões acerca da organização da vida interior refletida na ordenação dos tempos e espaços exteriores (2001, p. 35). A separação da sacralidade e dos contextos nãosagrados, primeira característica do homo religiosus, trata-se de um fenômeno sui generis, irredutível e significativo, a saber:

Primeiro argumento: "o sagrado" é um elemento da estrutura da consciência, e não um momento na história da consciência. Segundo: a experiência com o sagrado está indissoluvelmente associada ao esforço feito pelo ser humano para construir um mundo significativo. (ELIADE, 1989, p. 313)²

"Fist argument: 'The sacred' is an element of the structure of consciousness, and not a moment in the history of consciousness. Next: The experience of the sacred is indissolubly linked to the effort made by man to construct a meaningful world". 
A experiência do sentido radical, uma das reações do espírito humano, para Henri Delacroix (apud BASTIDE, 2006, p. 15), revela uma situação do ser humano em seu contexto histórico e cultural. Para Berger, o sagrado é apreendido como algo que "salta para fora" das rotinas normais do dia a dia, como algo de extraordinário (1985, p. 39). Há um processo de sacralização, uma experiência do sentido radical, constituinte do mundo do indivíduo mediado pela noção do sagrado - no caso, pelo peregrino que inclui em sua jornada visitações com fundo sacro. Tal processo sacralizante envolve uma separação ontológica radical daquilo que revela o sagrado - o objeto hierofânico - de todas as outras demais coisas. "O sagrado e o profano constituem duas modalidades de ser no mundo" (ELIADE, 2002, p. 26), sendo esta sendo constituição uma experiência existencial originária da posição do ser humano nos cosmos e da separação dos contrários, a quebra e ruptura de níveis, a mais primitiva polarização da realidade humana. Além da crítica marxista, há uma motivação intrínseca no ser humano, assumida aqui como o modelo exemplar da existência humana: a cisão radical nas modalidades da existência e configura o sagrado como o centro do mundo, o centro ontológico, o foco de toda ordem cósmica e harmônica na vida da pessoa religiosa (ELIADE, 2001, p. 106). A rigor, o que está em questão, neste momento, é a diferenciação do espaço sagrado - espaço bruto do turismo religioso na atualidade.

Sendo o paradoxo do sagrado a sua limitação no mundo material, isto é, a experiência do sagrado é mediada - e delimitada -por alguma parte da realidade finita, um sítio sagrado, por justamente portar e revelar o sagrado, o lugar no qual o sagrado se faz presente, tal sítio é ontologicamente separado qualitativamente das demais locações, ocupando um plano diferente e supernatural. $\mathrm{O}$ ato paradoxal da incorporação, segundo Eliade, é a condição mundana do sagrado, o espaço ao mesmo tempo físico e espiritual, criando, assim, uma condição dinâmica que será não apenas a própria condição da religião, como também a incorporação paradoxal destes espaços no turismo religioso. Dessa forma, a compreensão do sucesso do peregrino orienta-se pela busca incansável da dialética dos espaços, sagrados e profanos (RICKETTS, 2018, p. 34). Não apenas aquilo que se manifesta, isto é, o sagrado enquanto ordenação de espaço-tempo de uma experiência diferente da cotidiana, que carrega motivos para a união da separação, como também tudo aquilo que, apesar de profano, significa ao indivíduo uma profundidade sacra. Neste ponto, há uma virada para além dos templos. Para Eliade, a visitação, religiosa ou turística, a lugares sagrados não se restringe às práticas culticas, tampouco à manutenção estrita de uma fé ou religião específicas. A saber, monumentos de guerra, vítimas de genocídios carregam respeitos sacros nas representações humanísticas moder- 
nas, são, para Eliade, também lugares sagrados da ordem da experiência existencial originária, da vida interior e privada de cada indivíduo, podendo ou não se banhar em sacralidade institucional. Nesse caso, a existência ordinária do cotidiano diferencia-se pela sensação nostálgica da visita à terra natal, a casa de infância, o lugar do primeiro amor - em suma, um espaço e um tempo cuja sacralidade recai na individualidade vivenciada em saturação de sentido. (ELIADE, 2001, p. 15). A viagem aos espaços sagrados ou sacralizados remete, portanto, à jornada da aproximação do mundo interior com o mundo, se quisermos, superior, convergindo a aproximação e o distanciamento de mundo intermediado pela agenda de viagens intrínsecas ao programa da indústria do turismo.

Evidentemente, tal profundidade dialética entre espaço profano e espaço sagrado, ou seja, a significação dos espaços primordiais, em detrimento dos espaços corriqueiros, a busca pelo sentido de mundo, é explorada não apenas pelos sujeitos religiosos, como também pelos agentes de mercados correspondentes às viagens e movimentos motivados pela manifestação do sagrado. Em seus trabalhos a respeito do trânsito pelo espaço sacralizado, Marcel Mauss concluiu que “as coisas sagradas são coisas sociais” (MAUSS, 1994, p. 101). Por coisas sociais entende-se não apenas a esfera dos relacionamentos humanos, mas, também, um dossel ornamental, com todas as implicações da ordem da socialização, dentre elas, a comercialização da visitação de espaços sagrados. Paradoxalmente, ao invés da promoção do encontro genuíno e hierofânico, fortalece-se um mercado cujo interesse maior não ecoa com a experiência religiosa autêntica, mas, com o lucro interessado da indústria turística.

\section{Caminhos globais e locais: o caso do turismo religioso no Peru}

Na modernidade religiosa, segundo Hervieu-Léger, a subjetivação e individualização da crença $(2008$, p. 37 ), visando compreender como esse processo impactou a esfera religiosa, de certo modo, vivem um outro paradoxo, que não é aquele próprio do espaço sagrado: o enfraquecimento das instituições religiosas na tentativa destas em enquadrar os fiéis em seus dogmas. Parte-se de uma liberdade jamais vista, a saber, a construção da fé individual pelo próprio indivíduo. De um lado ou de outro, individual ou coletiva, a construção esteve presente em todas as fases da história, buscando oferecer à vida um mundo ordenado e habitável. Peter Berger, no prefácio de O Dossel Sagrado, pressupõe que "toda sociedade humana é um empreendimento de construção de mundo" (BERGER, 1985, p. 15). Tal pressuposição colocaria não apenas a religião, mas também o 
turismo, enquanto uma atividade humana, numa tarefa ontológica de ordenação de sentido para a existência. A religião e o turismo, deste modo, existem no espaço e usam o espaço para construir significados. Agora, a vantagem recai no turismo, uma vez que as viagens não são mais apenas orientações teológicas, mas também partem da expectativa individual e sincrética. Se as motivações do peregrino se sustentam por uma corrente subjacente de crença, as dos turistas, por sua vez, não são, necessariamente, as motivações de uma religião em especial, tendo na natureza de suas jornadas à lugares sagrados as fontes mais variadas: alguns, sim, buscam um engajamento espiritual genuíno, enquanto outros desejam compreender a natureza manufaturada da modernidade ou, ainda, carregam, simplesmente, uma atração pelo folclore cultural de um determinado lugar (RICKETTS, 2018, p. 34). Sendo o mundo humano imperfeitamente programado pela sua própria constituição (cf. BERGER, 1985, pp. 18-19), o mundo - novamente, a organização de um sentido primordial - é aberto e modelado pela atividade humana. Um espaço designado como sagrado e, portanto, separado de sua profanidade, mantém-se fixado geograficamente, ainda que seus significados comumente não sejam fixos devido a abertura do mundo. Classificar um espaço, em outra palavra, atribuir-lhe sentido, faz com que ele exista como lugar especial de sentindo. Sendo tal espaço sagrado, torna-se saturado de significação (RICKET'TS, 2018, p. 42).

Também contestado entre adeptos religiosos e turistas menos inclinados à espiritualidade e, por vezes, mesmo dentro de diferentes círculos eleitorais, por sua vez, o espaço, uma vez local de manifestação de princípios supremos, pode, ainda, segundo Peter Berger, estar investidos de status de sacralidade, mesmo se não mais assim o estão concebidos em termos pessoais (1985, p. 39). A história e a cultura carregam o status de sacralidade e permeiam o imaginário coletivo. A intervenção humana, neste caso, na operação turística, participa da construção e manutenção do lugar nos quais os destinos turísticos sagrados são fundamentais, promovendo, como veremos na dialética marxista, relacionamentos de reforçamento mútuo, os turistas e peregrinos que buscam locais sagrados desempenham papéis importantes na criação, manutenção ou contestação da identidade de um lugar. Segundo Hervieu-Léger, "a crença não desaparece, ela se desdobra, se diversifica” (2008, p. 54). Isto significa que, assim como a transmutação do espaço, a fé, enquanto experiência autêntica de atribuição de sentido, a despeito da manutenção dogmática, se desdobra e se diversifica conforme a história da cultura na qual a fé é inserida. A distinção entre espaço sagrado e profano implica, em resposta aos desdobramentos, uma dialética própria da condição humana, so- 
bretudo na experiência líquido-moderna da atualidade. O interesse pelo trânsito religioso não se restringe à esfera conceitual: ele se estende para a visitação física no movimento de um desdobramento interior do peregrino.

Exemplo disso é o turismo religioso no Peru - notadamente no que tem sido conceituado de incanismo. Apoiando-se em Perche (2012), o incanismo é uma forma ideológica que busca enaltecer o passado inca e todos os elementos associados à antiga tradição nativa - contudo, esse enaltecimento não teria uma origem nativa, quíchua, por assim dizer, mas sim exógena, formulado pela elite urbana cusquenha de língua espanhola, interessada em comercializar um produto turístico caracterizado por uma alteridade recriada. Em essência, a valorização do passado inca se insere na política neoliberal adotada pelo Estado peruano desde os anos 1990 no governo do presidente Alberto Kenya Fujimori, com o objetivo de abrir a economia nacional para atrair investimentos estrangeiros e inserir o país na rota dos fluxos turísticos globais.

A apropriação do espaço, enquanto transmissão de um patrimônio religioso e a formação de identidades religiosas na atualidade (HERVIEU-LÉGER, 2008, p 68) inclui, também, o controle - ou a tentativa de controle - do tempo desses espaços: não apenas a estipulação da duração do programa da viagem, como também o monopólio da experiência temporal e estruturante da significação desses espaços e do desdobramento interior dos indivíduos. A sacralização do mundo pela hierofania, a tentativa de apreender o tempo em templo, tempum et templum, conhece a manutenção dessas significações pela vivência do rito, nos cultos religiosos, nas celebrações festivas de cada narrativa religiosa, e caracteriza a heterogeneidade do tempo e sua reversibilidade. Esse movimento resulta em um novo horizonte, na pergunta de Hervieu-Léger: "como compreender ao mesmo tempo o processo histórico da secularização das sociedades modernas e o desdobramento de uma religiosidade individual, móvel e moldável que dá lugar a formas inéditas de sociabilidade religiosa?" (2008, p. 30) A questão, no coração da imagem do peregrino, situa não mais o monopólio da religião diante dos movimentos e ações humanas. Há, agora, um novo fator determinante para o trânsito; uma perspectiva até então sacralizada, agora do domínio do lazer contemporâneo. A crítica da apropriação do espaço sagrado pelo turismo religioso não é original: segundo Eliade, em Tratado de História das Religiões, o rito religioso é uma "manipulação do sagrado" (ELIADE, 2002, p. 6). Talvez, poderíamos inferir, o empreendimento turístico prolonga tal apropriação, valendo-se das noções mais originais da religião para o seu sucesso; em outras palavras, o tempo do espaço sagrado pretende ser um tempo original e originário de sentido, podendo 
com a reversibilidade preceder toda a reflexão sobre o mundo (ELIADE, 2001, pp. 25-26), agora, a serviço de uma indústria moderna.

É o caso apropriação turística das festividades incas do Inti Raymi - que na língua nativa significa a festa do Rei Sol. No passado, as celebrações ocorriam no solstício de inverno durante nove dias, em celebração pelas colheitas realizadas e para pedir que a terra fecundasse bem para as próximas safras. Em sua versão pós-moderna, no entanto, como o tempo da mercadoria não comporta os ritmos próprios das práticas tradicionais, a festa passou a ser realizada em um único dia, e, ao contrário de ser feita pelos nativos do lugar, começou a ser organizada pela Empresa Municipal de Festejos de Cusco (Emufec S.A.), que, em parceria com os ministérios do Comércio Exterior, Turismo (Mincetur) e Cultura do Peru, fizeram dela um grande espetáculo. Afinal, uma vez ao ano, o sítio arqueológico de Sacsayhuamán recebe cerca de 40 mil visitantes, que são acolhidos em arquibancadas especialmente montadas para uma encenação cinematográfica, na qual atuam 800 atores, de antigos rituais incas de sacrifício.

\section{O Turismo religioso no Brasil: das caravanas evangélicas à midiatização do catolicismo rústico}

Tal como no caso peruano, o turismo religioso no Brasil, também, se explica pelas características de uma sociabilidade liquefeita pelo consumo. Senão vejamos. Segundo dados do Ministério do Turismo brasileiro (Mtur), estima-se que, atualmente, 15 milhões de brasileiros viajem movidos pela fé. Em pesquisa realizada, em 2006, pelo mesmo Mtur, em parceria com a Fipe (Fundação Instituto de Pesquisas Econômicas), é possível observar um importante incremento do segmento num curto espaço de tempo. De acordo com a investigação, em 1998 o percentual de turistas que viajaram por motivos religiosos em território brasileiro era de $2,7 \%$, ao passo que, em 2006, o montante havia saltado para 3,2\% (PEREIRA et. all, 2008). E segundo números divulgados, em 2017, pela Secretaria Nacional de Qualificação e Promoção do Turismo, o território nacional abriga 300 destinos de turismo religioso, dentre os quais se destacam o santuário católico da Aparecida do Norte, que, em 2014, num ano recorde, chegou a receber 12 milhões e 200 mil devotos; as festividades do Círio de Nazaré na cidade de Belém, que chega reunir 2 milhões de fiéis em único dia; as romarias de Juazeiro do Norte e Canindé; e a encenação da Paixão de Cristo em Nova Jerusalém em Pernambuco, naquele é tido como o maior teatro ao livre do mundo - que, somados a outros destinos, geram um negócio de 4,4 bilhões de dólares decorrentes de 20 milhões de viagens nacionais por ano. 
De fato, o Brasil é um país que se destaca em termos de turismo religioso, e isso não somente porque possui uma das maiores populações católicas do mundo, mas também porque o segmento vem crescendo entre outros credos, a exemplo das confissões neopentecostais. Tanto em matéria de fluxos emissivos quanto receptivos o turismo evangélico tem, ao longo dos anos, apresentado considerável desenvolvimento. Um exemplo são as caravanas a Israel - que, somente em 2017, levaram 56 mil brasileiros à "Terra Santa”.

Segundo Frossard (2018), no Brasil, a criação de agências de viagens destinadas a esse público remonta à década de 1990 - caso das agências D’Ávila Tur, responsável por excursões organizadas por igrejas como a Renascer em Cristo, e da NewTur, que pertencia ao holding da Igreja Universal do Reino de Deus (IURD). Nos anos 2000, o número de agências especializadas aumentou consideravelmente, a exemplo das agências Terra Santa Viagens, US Travele TKR Viagens, para as quais as caravanas a Israel chegavam a representar $90 \%$ de todo o movimento financeiro do empreendimento (FROSSARD, 2018). A isso somase a criação de rotas de voos exclusivas, como era o caso da rota entre São Paulo e Tel Aviv, operada pela aérea israelense El AL - e hoje da LATAM, que de forma inédita para uma empresa da américa-latina passou a oferecer rota semelhante.

Teoricamente, dentre os motivos que formaram esse expressivo mercado, subjaz uma das principais características do consumo contemporâneo, qual seja: o processo tautológico e mimético no qual a própria vida de uma pessoa se transforma num veículo de comunicação para os outros - como se ela fosse um setor da indústria cultural, ao lado do cinema, da televisão, da rádio, etc. E, assim, nos tornamos, a um só tempo, atores e plateia de um ininterrupto espetáculo (GABLER, 1999).

Por isso, tem razão Frossard (2018) ao sublinhar o papel de "formador de opinião" exercido pelos pastores neopentecostais nas viagens turísticas a Israel. Afinal, eles se tornaram uma espécie de modelo de quem os fiéis devem replicar o estilo de vida. Não por acaso, figuras como Silas Malafaia, RR Soares, Edir Macedo, Renê Terra Nova, Ana Paula Valadão, Mara Maravilha passaram a ser consideradas celebridades gospel; de certa forma, agentes responsáveis pela organização do espaço que é sagrado e do tempo que é primordial. Disso resulta que:

O hábito de viagens dos líderes evangélicos para a Terra Santa se apresenta como um referencial para que os fiéis almejem participar de uma caravana. Estes líderes são o exemplo sobre a importância desta viagem, uma vez que eles próprios atribuíram valor a esse tipo de consumo ao realizarem tal deslocamento. E se houverem visitado múltiplas vezes este destino, mais 
credenciados esses líderes se apresentam, fato este evocado quando realizam anúncios, convites ou instruções sobre as caravanas para a Terra Santa, conferindo ainda maior credibilidade e confiabilidade ao produto e aos significados a este atribuído (FROSSARD, 2018, pp. 24-25).

No tocante agora ao fluxo receptivo, os números do turismo evangélico são igualmente eloquentes. Um exemplo são as peregrinações dirigidas ao recémconstruído Templo de Salomão, no bairro paulista do Brás. Não sem razão: com média de 400 mil visitantes por mês, a sede mundial da IURD já recebe mais pessoas do que tradicionais redutos do turismo religioso, como a Basílica Santuário Nosso Senhor do Bonfim, em Salvador, ou até mesmo o Cristo Redentor, no Rio de Janeiro, que recebe 3 milhões de visitantes por ano.

Em essência, a construção do templo de Salomão, na necessidade da instauração de um espaço sagrado par excellence, segue a mesma lógica dos seus congêneres católicos, espíritas ou budistas. Tal como o memorial Chico Xavier em Uberaba, o templo Zulai em Cotia e o Santuário Mãe de Deus de iniciativa do padre Marcelo Rossi em São Paulo, o templo iurdiano expressa um momento societário no qual a próprio templo religioso é incorporado às estratégias de marketing city e empreendedorismo urbano - assim tais empreendimentos são, antes de tudo, ícones urbanos para projetar dada cidade ou localidade na global divisão espacial do consumo. Ademais, como observa Gomes (2011), a representação mítica ao universo do Velho Testamento, de que se infere do próprio nome da sede da igreja de Edir Macedo, leva os fiéis a compreenderem o templo de Salomão como um lugar mais autêntico e próximo de Deus. Ato contínuo, a experiência de se frequentar o templo religioso acaba, assim, por se aproximar dos sentidos ideológicos da viagem turística contemporânea, quais sejam: o extraordinário, a fuga do cotidiano, o contato com o autêntico.

Além do turismo religioso católico e evangélico, entre nós, merece destaque, embora com menor expressividade, outros subtipos. É o caso do turismo de assombrações e visagens. Também pudera. Durante séculos o catolicismo brasileiro se desenvolveu segundo matrizes teológicas próprias - cujo isolamento só viria a ser superado no momento em que o esforço romanizador da Igreja católica se volta decididamente para os novos territórios cristãos em fins do século XIX - isto é, somente nos albores da primeira república. O importante a ser dito é que, no chamado catolicismo rústico brasileiro, a relação entre o mundo terreno e o transcendental é acima de tudo um convívio íntimo baseado em compromissos recíprocos e em troca de favores. Num mundo assim, periodicamente 
os mortos visitam os vivos, cobrando-lhes débitos não pagos, ao passo que fiéis e santos, crentes e padroeiros, vivem uma relação de amor e ódio - que naqueles tempos tanto estranhamento causava aos visitantes estrangeiro de temperamento cristão mais metódico. Ora, como explicar-lhes que aqui o menino Jesus, uma vez cultuado, costuma descer a escadaria do templo para ir dançar junto com os fiéis - ou que a carmelita Teresa de Liseux se abrasileirou e se tornou a nada palaciana Santa Teresinha? (HOLLANDA, 1995).

Soma-se a essa tradição religiosa, ainda muito arraigada no imaginário coletivo do brasileiro, o surgimento recente de um novo popular televisivo, caracterizado por combinar elementos da cultura de massa com elementos da cultura popular pré-televisiva. Nesse processo, o circo, a feira, a festa, o grotesco, as histórias de assombrações, enfim, tudo aquilo que restou do rural do Brasil colonial, acaba gerando "novos monstros chupa-cabras, ETs de Varginha e celebridades instantâneas" (BENTES, 2005, sem página). Não por acaso, portanto, o turismo de assombrações e visagens está se tornando uma moda - em quase todas as capitais brasileiras, de São Paulo ao Rio de Janeiro, de Recife a Belém, é possível encontrar roteiros turísticos que exploram economicamente as almas penadas que, todavia, habitam os seus centros históricos patrimonializados.

\section{O espaço religioso: uma nova mercadoria turística?}

Hervieu-Léger procura compreender como se dá a transmissão de um patrimônio religioso e a formação de identidades religiosas na atualidade, situando no indivíduo o seu principal agente da construção de crenças na formação de sua identidade (HERVIEU-LÉGER, 2008, p 39). Além de compactuar com as tendências abordadas, tal noção implica na autonomia do peregrino em meio as escolhas das opções do mercado, tanto religioso quanto comercial. O turismo religioso apresenta-se, neste cenário, como um espaço voltado para a experiência autêntica de uma vivência primordial, na tentativa de diferenciar-se dos demais produtos da sociedade.

No entanto, tal experiência não é, na ambiguidade do termo, gratuita. Enquanto um consumo característico da sociedade líquido-moderna, o turismo religioso inclui o indivíduo em sua estrutura mercantil, num processo no qual "é preciso primeiro se tornar uma mercadoria para ter uma chance razoável de exercer os direitos e cumprir os deveres de um consumidor" (BAUMAN, 2008, p. 89). Dessa forma, os membros da sociedade de consumo tornam-se eles próprios em mercadores para o consumo. Razão por que, no turismo religioso, os viajantes são os principais clientes e agentes da manutenção de uma economia de entretenimento, 
cuja ficção no cotidiano não se diferencia, estruturalmente, daquela em que as relações de troca e poder acontecem diariamente - afinal o capital é capaz de fagocitar todas as dimensões da vida social para fins de sua reprodução ampliada:

A sociedade burguesa é a mais complexa e desenvolvida organização histórica da produção. As categorias que expressam suas condições e a compreensão de sua organização permitem ao mesmo tempo compreender a organização e as relações de produção de todas as formas de sociedades passadas, sobre cujas ruínas e elementos ela foi edificada e cujos vestígios, ainda não superados, continua a arrastar consigo, ao mesmo tempo que desenvolve em si a significação plena de alguns indícios (MARX, 1999, p. 48).

Em face dessa dinâmica totalizante, não por acaso fala-se hoje em "urbanização turística" - utilizada para expressar uma nova forma espacial derivada da conexão entre o desenvolvimento de atividades turísticas e a emergência de novas paisagens urbanas no fim do século $\mathrm{XX}^{3}$. Esse movimento, por sua vez, seculariza os espaços religiosos e, de certa forma, paradoxalmente, sacraliza outros ao prometer a experiência de uma visitação diferenciada e autêntica, própria do tempo primordial de uma viagem - enfim à semelhança do que, historicamente, fez o que os frankfurtianos chamavam de indústria cultural, que definia, no campo da ideologia, novos valores de uso para realizar novos valores de troca, e como o faz agora a ideologia urbana ao criar uma maquilagem "antiprodutivista", "comunitária" e "neoruralista" para a transformação da natureza, da cultura, da memória, da história, da tradição, da religião, em novas mercadorias:

A imagem do inferno urbano que se prepara não é menos fascinante, e as pessoas se precipitam em direção às ruínas das cidades antigas a fim de consumi-las turisticamente, acreditando, desse modo, curar a saudade que sentem [...]. Eis uma vida cotidiana bem decupada em fragmentos: trabalho, transporte, vida privada, lazeres (LEFEBVRE, 2006, p. 97).

3 Mullins (1991), ao estudar a costa australiana, afirma que os espaços turísticos representam uma forma totalmente nova de urbanização, haja vista que não são organizados para a produção, como o foram as cidades industriais, mas sim para o consumo de bens e serviços - notadamente simbólicos. O pesquisador recolheu dados referentes a 13 cidades australianas. Nas cidades de Gold Coast e Sunshine Coast, cujas economias giravam em torno da atividade turística, o autor verificou algumas características que as diferenciavam das demais, dentre as quais, vale destacar, o crescimento demográfico e econômico acima da média nacional, a importância política de segmentos médios ligados ao setor de comércio e serviços que lideravam o debate local em função de seus interesses, e o aumento da desigualdade social, devido ao incremento de formas precárias de trabalho que caracterizam o setor - baixo índice de sindicalização, trabalhos temporários, baixos salários, etc. 
É importante frisar que não se trata do consumo de qualquer mercadoria, e sim do consumo do próprio espaço, que passa a ser produzido para esse fim. No caso específico do turismo religioso, a produção não diferencia espaço sagrado de espaço profano, muito menos respeita os limites da natureza. Antes disso, em termos benjaminianos, não importa quão aurático seja o espaço, porquanto o objetivo é a sua plena aquisição e subordinação, em beneplácito do sucesso turístico pretendido.

Há poucos anos não se podia imaginar outra produção que não fosse a de um objeto, localizado, aqui e ali, no espaço: um objeto do usual, uma máquina, um livro, um quadro. Hoje, o espaço inteiro entra na produção como produto através da compra, da venda, da troca de parcelas do espaço [...] (LEFEBVRE, 2004, p. 142).

Em face disso, por mais paradoxal que possa aparecer, não é de se estanhar o fato de que o trade turístico passe a explorar inclusive - e sobretudo - práticas religiosas que, em um dado momento da história, foram reprimidas para fazer deslanchar indústria cultural brasileira. É o caso do turismo religioso ligado às tradições afro-brasileiras. No estado da Bahia, por exemplo, conforme aponta Correa (2017), os terreiros de candomblé já são tratados como patrimônio cultural e atrativo turístico. Mais ainda. De acordo com o Centro de Estudos Afro-Orientais da Universidade Federal da Bahia (UFBA), há hoje em Salvador um total de 1.165 terreiros cadastrados que podem ser frequentados por visitantes (RODRIGUES, 2016). $\mathrm{Na}$ capital baiana, há inclusive produtos turísticos que vão desde uma consulta aos búzios a uma visita a um terreiro de candomblé, passando por leitura de cartas, vidência na água, limpezas, descarregos, desobsessões (LUPINACCI, 2002).

Ademais, a Bahia foi o primeiro estado brasileiro a lançar um programa de desenvolvimento para esse tipo de turismo - quando em 2007, por iniciativa da secretaria estadual de turismo, foi inaugurado o Programa de Ação do Turismo Étnico Afro da Bahia, voltado para a visitação dos terreiros de candomblé de Salvador e do Recôncavo Baiano (CARVALHO; AVILA, 2012).

Afora a Bahia, o estado do Rio de Janeiro também se posiciona como potencial centro de turismo étnico-religioso. É o caso das visitações aos terreiros da cidade de São Gonçalo, conforme descrito por Correa (2017) e das festividades de louvor a Iemanjá na capital fluminense - conforme nos relata Vieira (2015) por ocasião da $48^{a}$ edição da festa na cidade do Rio de Janeiro, quando centenas de pessoas entre fiéis e turistas participaram do cortejo que partiu da Cinelândia até a Praça XV, terminando na entrega dos presentes à divindade na baía de Guanabara. 
Enfim, num país onde, historicamente, o universo lúdico-religioso do negro foi objeto de repressão - basta lembrar que tanto a capoeira quanto os batuques eram tipificados penalmente no ordenamento jurídico do período da primeira República -, os orixás, o lundu, o candomblé, uma vez mercantilizados e redimidos pela abstração do mundo da mercadoria, passam agora a ser objeto de curiosidade do olhar do turista - em que pese o fato, é verdade, da violência estatal que se abate, cotidianamente, sobre os lazeres das comunidades negras nos centros urbanos e metropolitanos do Brasil.

\section{A eternidade como experiência turística}

À luz de todos esses exemplos de turismo religioso ao redor do globo, fica claro, portanto, que vivenciamos um interregno nos assuntos da fé - e, como é próprio desses estágios, as antigas categorias que utilizávamos para separar a religião do mercado, o turista do peregrino, a fé do espetáculo, e assim por diante, parecem guardar pouco valor heurístico diante da novidade que a sociedade liquido-moderna anuncia. Para a religião, o turismo tem representado uma nova forma de difusão e recrutamento de novos fiéis, e, sobretudo, uma maneira de assegurar o seu papel num mundo dominado pela ciência e pela tecnologia. É neste ambiente onde uma nostalgia por um passado primordial e a inclinação para a sensação de eternidade promovem a intersecção entre o turismo religioso e a fissura ontológica preenchida espacial e temporalmente por tal empreendimento.

Não é a intenção do artigo discutir a temporalidade. Tantos outros pensadores fizeram a discussão a respeito da natureza do tempo com maestria, a saber, Santo Agostinho a intentio e distentio da alma, Nietzsche e o eterno retorno, Bachelard e a intuição do instante, Unamuno e o desejo de não morrer. Entretanto, há um recorte temporal na atividade turística, ainda mais no turismo religioso. Se comparada ao movimento religioso do peregrino, há uma busca por uma integração total, isto é, a inserção no real, por parte do viajante. Mircea Eliade, em Yoga: Imortalidade e Liberdade, ao analisar a disposição humana para a busca de tempos primordiais, atesta haver um retorno à unidade, constituinte do objetivo supremo de toda existência responsável (1996, p. 112). Aqui vale destaque para um texto raro a respeito da atividade turística encontrado nos diários de Mircea Eliade:

O fascínio da viagem deriva não apenas do espaço, das formas e das cores - dos lugares por onde alguém passa ou através dos quais se viaja - mas também do número de "tempos” pessoais que uma pessoa reatualiza. Quanto mais eu avanço na vida, mais tenho a impressão de que as viagens acontecem, concomitantemente, no tempo e no espaço. Uma paisagem, uma 
rua e um determinado evento certamente têm sua frescura e seu charme, mas, ao mesmo tempo, liberam inúmeras recordações - algumas aparentemente sem qualquer interesse, mas não menos comoventes e, por fim, preciosas; é assim que se recuperam fragmentos esquecidos ou negligenciados de uma "história pessoal". Em certo sentido, quando viajo por espaços geográficos conhecidos ou desconhecidos, viajo ao mesmo tempo no passado, na minha própria história. O que me encanta nessa anamnese é que ela é produzida e nutrida por viajar em primeiro lugar pela a sua espontaneidade; torna-se possível antecipar ou especificar qual fragmento do passado será devolvido a mim no final de uma rua pela qual eu caminho. Quando entro em uma catedral, nunca sei se encontrarei ali a lembrança de outros santuários vistos em tempos passados - ou se me lembrarei de um livro ou de um homem de quem não penso há anos, que captarei eu mesmo ouvindo uma velha melodia, uma conversa há muito esquecida. [...] Seria isso apenas uma questão da recuperação do passado? Pode ser que o processo seja mais complicado e mais sutil: uma jornada que ocorre em diferentes paisagens, formas e cores, despertaria uma série de associações tão preciosas para a história secreta da alma quanto são, numa análise junguiana, as associações trazidas pela audição de certas palavras, nomes, lendas ou mitos, ou como é a contemplação de certas pinturas ou desenhos. (ELIADE, 1989, pp. 326-327). ${ }^{4}$

A viagem exterior reflete a viagem interior. O movimento, cujo ponto de partida e de chegada parecem estar no mesmo lugar, ultrapassa julgamentos ex-

4 The fascination of travel derives not only from space, forms, and colors - the places on goes or through which one travels - but also from the number of personal "times" one reactualizes. The more I advance in life, the more I have the impression that journeys take place, concomitantly, in time and space. A landscape, a street, and an event certainty have their freshness and their charm, but at the same time they release innumerable little memories - some apparently without any interest, but no less moving and ultimately precious; it is thus that one recovers forgotten or neglected fragments of a "personal history". In a certain sense, when I travel through familiar or unknown geographic spaces, I travel at the same time in the past, in my own history. What delights me in thus anamnesis brought about and nourished by traveling in first of all its spontaneity; it is possible to anticipate or specify what fragment of the past will be given back to me at the end of a street in which I walk. When I go into a cathedral I never know if I will find there the memory of other sanctuaries seen in days gone by - or if I will remember a book or a man of whom I have not thought for years, of it I will catch myself hearing an old melody, a conversation long forgotten. [...] Is it a solely a matter of that, of the recovery of the past? It could be that the process is more complicated and more subtle: a journey which takes place across different landscapes, forms, and colors, arouses a series of associations just as precious for the secret history of the soul as are, in a Jungian analysis, the associations brought about by hearing certain words, names, legends, or myths, or as is the contemplation of certain paintings or drawings. 
teriores de instituições e sacralidade. Haveria, na motivação de quem viaja, uma busca de característica regressiva em direção a uma origem primodial de significação. Eliade é um bom exemplo da individualização narrativa de Hervieu-Léger a respeito da transmissão de um patrimônio religioso e, principalmente, a respeito da formação de identidades religiosas na atualidade. No caso das religiões, o retorno às origens tornaria a consciência humana - e, consequentemente, as formações de identidades religiosas atuais - cíclicas. A finalidade da vida, em resposta viajante à liquidez do mundo vivido, apresenta-se como uma origem. "O essencial é que há sempre uma concepção do fim e do princípio de um novo período do tempo, baseada na observação dos ritmos cósmicos", ELIADE, 2001, p. 67). A temporalidade renova-se periodicamente pelo retorno às origens, repetição de atos cosmogônicos - daí provém, na sacralização do mundo, questões de novo nascimento, tentativa de restauração do mundo, tempo mítico, orientatio e negação da história. O tempo apresenta-se de diversas maneiras, reservando aos hebreus os primeiros a descobrir o significado da história como epifania de Deus (ELIADE, 1990, p. 119) e, com o profetismo, pela primeira vez uma religião valorizaria a história em sua materialidade. A circularidade da história antiga e grega perde espaço para as tradições monoteístas, em especial a cristã, onde a história torna-se linear e teleológica. A ritualização e inserção do indivíduo no tempo responde alguns aspectos da historicidade humana para buscar um tempo primordial no embaralhamento atual. As religiões perdem a dimensão histórica e preferem um arquétipo - "modelo exemplar" - vivencial, renovado, em direção ao eschaton final.

O sujeito religioso dirige-se periodicamente aos arquétipos, aos estados "puros"; consequentemente, há uma tendência em retornar ao primeiro momento, à repetição do que estava no início. Porquanto se não forem compreendidas as funções de "simplificação" e "arquétipos" dos retornos, repetições e recomeços, nós não compreenderemos como a experiência religiosa e a continuidade do divino são possíveis - resumindo, como é possível ter uma bistória e uma forma na "religião". (ELIADE, 1990, p. 20)

A peregrinação atual aponta para uma espécie de princípio primordial. Quase uma experiência in illo tempore, isto é, naquele tempo, o turismo proporciona um retorno ao tempo que deveria ser pleno. O turismo religioso, em sua matriz, orientada pela percepção do espaço primordial e do tempo original, promove um recomeço no tempo laboral do peregrino atual. Em um ambiente líquido-moderno, contrário aos planejamentos e ao armazenamento cultural, uma simplificação dos arquétipos pela atividade turística confere importância à satisfação dos desejos ou a 
tentativa de satisfazê-los no agora. Aqui, tempo e espaço são indissociáveis, sobretudo na medida de um mercado que se beneficia da confusão de ambos. O tempo pontilhista, expressão de Michel Maffesoli, que significa um pontuado - conforme Nicole Aubert -se traduz numa percepção temporal por rupturas e descontinuidades. Ao contrário da linearidade temporal, de Eliade, ou, ainda, como esboçou Santo Agostinho em sua aporia do "tempo da alma" e do "tempo do mundo", na sociedade líquido-moderna, cujo alicerce é a estratégia existencial consumista, a vivência individual torna-se uma sucessão de presentes no qual a expectativa pelo futuro dá lugar a uma experiência do desempenho individual (BAUMAN, 2008, p. 74). A sede pela vivência eterna no instante do presente, pautada pela tarefa individualmente empreendida e resolvida com a ajuda de habilidades e padrões de ação de consumo individualmente obtidos (cf. BAUMAN, 2008, p. 74), é o que assegura, em última instância, a busca por um atrativo turístico. Com efeito, consumir na sociedade líquido-moderna é investir em si próprio: investimento constante, não-linear, e, frise-se, necessariamente presente.

Embora o turismo religioso e espiritual indique viagens realizadas exclusivamente ou principalmente por razões religiosas, o "turismo de base religiosa" reconhece que os turistas não são homogêneos; os turistas cujo objetivo principal é a recreação ainda podem ser adeptos religiosos, turistas não religiosos ainda costumam visitar um local sagrado por causa de suas supostas qualidades nominativas, e aqueles cujo objetivo principal é religioso ainda podem evidenciar comportamentos tipicamente associados ao turismo. "Turismo para lugares sagrados" ou "turismo sagrado" permite a flexibilidade de incluir lugares consagrados que são formalmente religiosos ou não. De fato, os locais de peregrinação secular continuam a proliferar, em que "peregrino" é usado indistinguivelmente de "turista" por causa da mistura de secular e sagrado no próprio local, bem como as diversas motivações das pessoas que viajam para lá. Um exame espacial do turismo para locais sagrados deve, portanto, considerar a dinâmica espacial das motivações e ações das pessoas dentro de um lugar mercantilizado e contestado que atrai turistas, peregrinos e muitos que são ambos. Curiosamente, os espaços sacralizados dão lugar para um tempo que pretende ser sagrado, como também, nesta dinâmica criativa e feroz, típica do capitalismo, sacraliza-se outros espaços cujas promessas proporcionariam, igualmente, a sacralização de um tempo primordial na divisão do trabalho da sociedade.

Pode-se, assim, falar de um turismo com pretensões sólidas, mesmo que este, em sua praxis, reforce o mundo líquido atual. Segundo Bauman, "apenas bens de fato duráveis, resistentes e imunes ao tempo poderiam oferecer a se- 
gurança desejada" (2018, p. 43) A expectativa existencial por fatos duráveis e segurança individual, enquanto experiência fundante em um mundo fundado no mercado, participa da experiência turística, que, por sua vez, transformou o turismo religioso num pujante nicho de negócios e uma oportunidade de romper com as sazonalidades dos modelos massificantes ligados às estações do verão.

No fundo, concordando com Hervieu-Légere (apud SILVEIRA, 2007), o fato é que estamos diante de um profundo processo de dessimbolização na esfera religiosa - que, a nosso ver, longe de sugerir o fim da religião no interior de uma sociedade totalmente laicizada pela força dessacralizadora da mercadoria, paradoxalmente, tem trazido à sociedade laica uma nova forma de religiosidade, não necessariamente ligada a dogmas ou sistemas teológicos, mas baseada em experiências e sensações como, por exemplo, a de uma viagem turística. Essas viagens, conforme notou Bauman pela dinâmica da sociedade atual, buscam um presente inesgotável, um presente do presente. Ou, se quisermos, nas palavras de Eliade, a respeito da sua experiência temporal vivenciada ao revisitar a sua amada Índia, não mais idêntica à sua experiência da juventude, agora modificada pelo tempo, "se a Índia 'histórica' estava proibida para mim, o caminho estava aberto para a Índia 'eterna"' (ELIADE, 1990b, p. 198).

\section{Considerações finais}

Em Vida para Consumo, Bauman expõe uma trágica realidade sobre a sociedade líquido-moderna, até então ofuscada pelo mercado de consumo: a da transformação dos indivíduos em mercadorias. Se tudo é objeto de curiosidade turística (URRY, 1997), os espaços religiosos não ficariam isentos de tal curiosidade. E se a vida atual é orientada pelo consumo (BAUMAN, 2008, p. 34), não surpreendentemente, o peregrino cairia numa indústria voltada para a manutenção e visitação dos espaços sagrados, bem como na atribuição sagrada de espaços ainda não sacros. A rigor, o objetivo principal da sociedade de consumidores é a "comodificação" ou "recomodificação" do consumidor. O sagrado, neste horizonte, apresenta-se como uma forma de legitimizar o consumo, como também proporcionar a experiência do espaço autêntico e do tempo primordial para o peregrino. A tragédia da religião é participar com os seus espaços e tempos sagrados na manutenção da sociedade líquido-moderna e na estrutura turística social. Notou-se, assim, a não-ingenuidade do mercado turístico, mesmo tendo, por outro lado, a omissão da lógica mercantil intrínseca nos processos de visitação, lucro e comodificação do saber religioso por parte dos líderes e das instituições. Ao final da referida obra, Bauman questiona se os valores subjetivos da 
vida humana poderiam ser negociados e comercializados como produtos de um mercado (2008, pp. 186-194). O oposto é, também, questionável: se o comércio, sobretudo do espaço sagrado - e, principalmente, e da sacralização do espaço pelo turismo -, poderiam elevar os valores subjetivos da vida humana. Pelo menos, no que foi explorado, mundial e localmente, os dados mostram outras forças nas relações de troca e visitação dos sítios mais explorados pela indústria turística que se perdem na experiência existencial originária dos peregrinos.

O processo civilizador, conforme exposto por Norbert Elias - de quem Bauman extrai as suas críticas acerca da sociedade de consumidores líquido-moderna -, enfatiza a participação do nascimento do "eu moderno", a soberania da auto-narrativa, no processo de consumo intrínseco aos mercados. O peregrino é aquele que constrói narrativamente a sua experiência, descolado da mediação dogmática, agora em uma "laicidade mediadora", para doar sentido à sua existência. Evidentemente o turismo religioso não promove um novo axis mundi na experiência líquido-moderna de sociedade. Entretanto, aproveita-se das exigências da modernidade, que impõe ao peregrino a produção de significados para a sua própria existência (HERVIEU-LÉGER, 2008, p. 185), enquanto o eixo articulador das viagens turístico-religiosas. Pretende-se, assim, a apropriação da verdade interior do indivíduo, com sua autoconfiança e desejo por bens de fato duráveis, resistentes e imunes ao tempo, como um tipo de resistência - e, paradoxalmente, manutenção - da sociedade líquido-moderna. Ao contrário de alcançar novos horizontes, distancia-se do Sitz im Leben, o lugar do qual, evitando-se a profanação espaço-temporal, poderia ser o início da transformação sólida do insólito - enquanto que, na realidade, camufla outra indústria, tão feroz e sagaz quanto àquela evitada, agora aproveitando-se da fluidez das decisões para explorar a importância mais elevada: uma viagem de retorno a um mundo originalmente sagrado, agora humanamente profano pela apropriação da fé pelo trade turístico.

\section{Referências}

BASTIDE, Roger. O sagrado selvagem e outros ensaios. São Paulo: Companhia das Letras, 2006, 275p.

BAUMAN, Zigmunt. Vida para consumo: a transformação das pessoas em mercadoria. Rio de Janeiro: Zahar, 2008.

BENTES, I. A pobreza criadora do folkmídia. Folha de São Paulo. São Paulo, 23 jan. 2005. Disponível em: <https://www1.folha.uol.com.br/fsp/mais/fs2301200502.htm> Acessado em 12/04/2018. 
BERGER, Peter. O dossel sagrado: elementos para uma teoria sociológica da religião. São Paulo: Paulus, 1985.

CARLOS, A. F. A. A (re) produção do espaço urbano. São Paulo: Edusp, 2008. 270p.

CARVAlHO, R. C. O.; AVILA, M. A. O Turismo Étnico e seus reflexos nos Terreiros de Candomblé Angola em Salvador -Bahia. Políticas Culturais em Revista, n.1, v. 5, pp. 58-90, 2012.

CORREA, D. M. G. O turismo religioso em sua nova face: o candomblé. 91f. 2016. Monografia (Graduação em Turismo) - Faculdade de Turismo e Hotelaria, Universidade Federal Fluminense, 2016.

DIEGUES, A. C. O mito moderno da natureza intocada. 3. ed. São Paulo: Hucitec, 2001. 169p.

ELIADE, Mircea. Autobiography, Volume 1: 1907-1937, Journey East, Journey West. Chicago: University of Chicago Press, 1990b, 347p.

ELIADE, Mircea. Journal I: 1945 - 1955. Chicago: The University of Chicago Press. 1990, 219p.

ELIADE, Mircea. Journal II: 1957 - 1969. Chicago: The University of Chicago Press. 1989, 343p.

ELIADE, Mircea. O sagrado e o profano. São Paulo: Martins Fontes, 2001, 191p.

ELIADE, Mircea. Tratado de história das religiões. São Paulo: Martins Fontes, 2002, 479p.

FOLLIS, R. Turismo religioso, adventismo e lugares de memória. Revista Horizonte (Revista de estudos de teologia e ciências da religião da PUC-MG), Belo Horizonte, v. 16, n. 49, pp. 38-65, 2018.

FROSSARD, M. S. Celebridades gospel e o turismo evangélico: os líderes de opinião como fonte de significados para as caravanas evangélicas à Terra Santa. Revista Horizonte (Revista de estudos de teologia e ciências da religião da PUC-MG), Belo Horizonte, v. 16, n. 49, pp. 14-37, 2018.

GABLER, N. Vida - o filme: como o entretenimento conquistou a realidade. São Paulo: Companhia das Letras, 1999.

GOMES, E. A era das catedrais. Rio de Janeiro: Garamond, 2011.

HERVIEU-LÉGER, D. O peregrino e o convertido: a religião em movimento. Petrópolis: Vozes, 2008 .

HOLANDA, S. B. Raízes do Brasil. 26. ed. São Paulo, SP: Companhia das Letras, 1995.

PERCHE, G. Cuando el cuy tuvo que salir de la cocina: turismo e intimidade na ilha de Amantani, lago Tititaca, Peru. In: ASENSIO, R.,H.; GALAN, B.P. (orgs). ¿El Turismo es cosa de pobres? Tenerife: Revista de Turismo y Patrimonio Cultural. 2012, pp. 201-224. 
LEFEBVRE, H. A revolução urbana. Belo Horizonte: UFMG, 2004. 178p.

LEFEBVRE, H. Reprodução: as relações de produção. Porto/Portugal: Publicações Escorpião, 1973. 115p.

LUPINACCI, H. H. Rota mística de Salvador lava a alma. Folha de São Paulo. São Paulo, 12 ago. 2002. Disponível em:

<https://www1.folha.uol.com.br/fsp/turismo/fx1208200201.htm> Acessado em 15/03/2018.

LYOTARD, Jean-François. La condition postmoderne : rapport sur le savoir. Paris: Editions de Minuit, 1979.

MARX, K. Para uma crítica da economia política. São Paulo: Coleção Ridendo Castigat Mores (versão para eBook), 1999. 63p.

MARX, K. O capital: o processo de produção do capital. 23. ed. Rio de Janeiro: Civilização Brasileira, 2006. 571p.

MAUSS, Marcel, HUBERT, Henri. Sacrifice: Its Nature and Function, Chicago: The University of Chicago Press, 1994.

MULLINS, P. “Tourism urbanization”. In: International Journal of Urban Regional Research, n. 3, v. 15 , p. $326-342,1991$.

PEREIRA, T. M. et. al. Turismo religioso: análises e tendências. In: Seminário da Associação Nacional de Pesquisa de Pós-Graduação em Turismo, 5., 2008, Belo Horizonte. Anais... Belo Horizonte: UNA, 2008. pp. 1-13.

PUCHNER, Martin. The Written World: The Power of Stories to Shape People, History, Civilization. New York, Random House, 2017.

RICKETTS, Jeremy R. 2018 “Tourism to Sacred Places in America: A Spatial Analysis.” In: Oxford Research Encyclopedia of Religion. Oxford University Press. < http://oxfordre.com/religion/ view/10.1093/acrefore/9780199340378.001.0001/acrefore-9780199340378-e-541> Acessado em: 24/10/2018

RODRIGUES, D. G1 lista terreiros de candomblé na BA e dá dicas para frequentar templos. G1. Salvador, 30 nov. 2016. Disponível em:

<http://g1.globo.com/bahia/noticia/2016/11/g1-lista-terreiros-de-candomble-na-ba-e-da-dicas -para-frequentar-templos.html> Acessado em 24/05/2018.

SALCEDO, J. V. Turismo en Cusco: Fuente de dinero y conflictos. Larepublica. Lima, 28 out. 2018. Disponível em:

$<$ https://larepublica.pe/sociedad/1346197-turismo-cusco-fuente-dinero-conflictos> Acessado em $05 / 06 / 2018$. 
SANTOS, M. G. M. P. Turismo religioso e lazer: delimitação e aproximação. Cadernos de Geografia, Coimbra, n. 19, pp. 97-111, 2000.

STEIL, C. A. Peregrinação, Romaria e Turismo Religioso, Raízes Etimológicas e Interpretações Antropológicas. In: ABMANSSUR, E. S. (org.) Turismo Religioso: ensaios antropológicos sobre religião e turismo. Campinas: Papirus, 2003, pp. 29-51.

VIEIRA, I. Devotos celebram dia de Iemanjá no Rio de Janeiro. Agência Brasil. Rio de Janeiro, 04 fev. 2015. Disponível:

$<$ http://agenciabrasil.ebc.com.br/direitos-humanos/noticia/2015-02/devotos-celebraram-dia-de -iemanja-no-rio-de-janeiro?amp> Acessado em 22/05/2018.

URRY, J. O Olhar do Turista: lazer e viagens nas sociedades contemporâneas. 3. ed. São Paulo, Studio Nobel, 2001. 